\title{
Early Admission Call-Up: A Strategy And Marketing Perk For Attracting Better Students To A College In Lebanon
}

\author{
Viviane Naimy, Notre Dame University, Lebanon
} Ramzi Nasser, Notre Dame University, Lebanon

\begin{abstract}
The purpose of this study was to determine whether an early call-up strategy helps in attracting better students to a private university in Lebanon. Early admission call-up was administered to the top 25 percentile-ranked students of main feeder schools at a private university in Lebanon. Admission data was accrued for students who applied for admission from 2000 to 2006. The early admission call-up was made in the spring of 2006 and compared to the top 25 percentile-ranked students of previous years that were not treated with the early-admission call-up. They were also compared to those below the 25 percentile score cohort group. The results showed that students who were treated with the call-up enrolled at higher rates than those at the top 25 percentile rank in previous years. It was also shown that those at the top 25 percentile score had a higher high school averages as compared to the previous years. Early admission call-up provides a strategic marketing "perk" to enrolling above average students at a private university in Lebanon.
\end{abstract}

Keywords: Early Admission, Admission Call-Up, Marketing Strategy, Quality of Students

\section{INTRODUCTION}

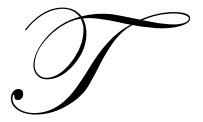

raditionally, research in college enrollment has been limited to the study of three factors: a student's application decisions, institutions' acceptance decisions, and college choice. However, rarely have studies come out to report whether these conditions affected by what colleges can offer in a way to market their programs and provide "perks" for future students. Thus, early admission call-up as a way that universities use to attract students to programs constitutes an important factor that might affect a student's decision to enroll at a university.

The challenge of many private universities is to select students who are most likely to succeed in college and make a significant contribution to their field of study. In many countries, admission to private universities is open and many admission officers may seek students who have sub-standard qualification, as measured through secondary school performance. Universities that often reach maturation cycles go through a process of program development, quality checks, and they do so with the goals of bettering their academic programs by enrolling "better students". One method used extensively in American universities, known as the early admission, allows the student to apply early and is then admitted early. In return, the student commits or agrees to enroll at the university of choice at an early stage. The early admission call-up, as used within the context of this study, is a treatment for attracting students. Early admission in Lebanon is different in its function when compared to the U.S. The early admission allows the student to apply early, which commits the university to saving the student a place at the university, but does not provide the early admission agreement.

Student characteristics can influence the institution in forming its identity and character (Berger \& Milem, 2000). Thus, better performing students create a better academic atmosphere for students and faculty. According to 
Harman (1994), the selection of top-ranking students will generally impact the quality of internal working of a university. Early admission is a key and vital institutional strategy in getting the most qualified students enrolled in a university. In addition, early admission call-up provides a variety of other services for first-come-first-serve as in housing, financial aid, or even a place in highly competitive programs such as engineering or medicine. The economic returns of a successful student greatly impacts the economic returns transcended through occupational success and career advancement. Seeking the "right" student may produce significant economic and social returns for the economy and nation at large. Thus, selecting a student who has greater potential to succeed in college produces conditions, if amortized over the working life spans of graduates, may show a far better and less expensive in both economic and social terms.

\section{Conceptual Framework}

Follow-up with students' may exhibit different enrollment behaviors compared to regular and voluntary admission processes. The implementation of the merit-based early admission process based on high school rank; i.e. grades, could likely affect student pathways to academic success and provides the university with increased enrollment of top ranking students from secondary schools.

Typically, American-style universities admit students based on evidence of high school grade point average, entrance exam scores, and rank in class. These three main factors help admissions officers to build a composite score that constitutes an indicator to student performance. Many private universities, who follow the American-style universities, evaluate language skills and logical and mathematical abilities through different high school disciplines. However, universities vary in ways and systems. Criteria of higher education institutions have a wide spectrum from competitive examination to open admission. The early admission concept, within this case study, seeks students who have certain qualities desired in non-competitive admission environments.

Almost three decades ago, admission to universities in the Middle East was highly selective because of greater demand, and low supply. However, in times of rapid changes, higher education institutions growth has profoundly changed the landscape of higher education in Lebanon and the Middle East. Admission and selectivity in most universities in Lebanon is somehow lax. While, a number of universities use a variety of means to select students based on school records and performance on standardized local and international tests, many of them, whether located in Lebanon or in other countries in the Middle East have opened their doors to students with substandard requirements. The mushrooming of American-style universities in Lebanon and other parts of the Middle East such as in the United Arab Emirates (UAE) may seek the best students but settle for substandard requirements. Thus, using early admission is one way to attract students to non-competitive programs. In fact, little is known about early admission call-up and its impact within the academic performance of students in Lebanon and elsewhere. The main premise is that the early admission call-up encourages access to higher education among different sub-populations of students. It is hypothesized that these call-ups attract students to the university by affecting their initial choice and can be used as a marketing perk to attracting top students.

The purpose of this study was to examine the nearly enrolled students who went through the early admission call-up in a private university in Lebanon for the 2007-2008 academic years compared to previous academic years covering the 2000-2007 period. The study compares students who were ranked in the top 25th in their school that were provided with an early admission "call-up" initiated in 2006-2007 for the academic year 20072008 with those at top 25 th in their schools who were not "treated" with the early admission call-up.

\section{DATA AND METHODOLOGY}

In 2006, all school principals of the main feeder $\operatorname{schools}^{1}$ to a private university were sent a letter requesting them to supply the university a list of students in the top 25 percentile rank in their secondary class. Once the list of students was received in early autumn of the academic year 2006-2007, these students were sent letters to their schools and handed out to them individually as an early admission call. The letters indicated that their "seat" at

\footnotetext{
${ }^{1}$ Main feeder schools is defined as being those which feed the largest number of students to this university over the past five years.
} 
this private university was reserved, provided they fulfill the admission requirements. From the list of students ranked at the top 25 percentile who received an early admission call-up, 107 students applied to the university. These students were then followed through to see if they enrolled or did not enroll. The data of the early admission group was compared to a cohort group $(n=443)$ of students who were not at the top 25 percentile rank of their secondary school class and who applied in the fall semester of the academic year 2007-2008 from the main feeder schools.

Then, a cohort of the early admission group, of those who enrolled was also compared to a cohort of enrolled students who applied from previous years, since 2000-2001 ( $n=1641)$ from the main feeder schools. The latter comparison was based on the percentage and secondary school averages as grouped at the top and below the 25 percentile rank. The 2007-2008 academic year cohort was used as the datum of comparison with the previous years.

\section{RESULTS}

\section{Enrolled/Not Enrolled with Early Admission Call-up Vs Non-Early Admission Call-Up}

A count was calculated for those who enrolled or did not enroll for academic year 2007-2008 crossed by a two-rank classification:

1. those below the 25 percentile rank, and

2. those above the 25 percentile rank who went through the early admission call-up.

The data showed that $77.5 \%$ of students who were at the top 25 percentile score enrolled at that private university. On the other hand, $79.45 \%$ of students below the 25 percentile rank (non-early admission call-up) enrolled (See Table 1).

Table 1: Early admission call-up by enrollment for 2007-2008

\begin{tabular}{|l|c|c|c|}
\hline \multicolumn{1}{|c|}{ Early Admission } & Did not Enroll & Enrolled & Grand Total \\
\hline Non-Early Admission Call-up (below the 25 percentile rank) & 91 & 352 & 443 \\
\hline Early Admission Call-up (Above the 25 percentile rank) & 24 & 83 & 107 \\
\hline Total & 115 & 435 & 550 \\
\hline
\end{tabular}

\section{Number of Enrollees Above and Below the 25 Percentile Score}

In the second analysis the growth rate of enrollees ranked above or below the 25 percentile score in their high school classes was calculated.

The results show that for the academic year 2007-2008, students at the top 25 percentile rank (with early admission call-up) increased by almost $66.82 \%$ from $2006-2007$. Of the total number of students who came from the top-feeder schools $(n=435)$ for the 2007-2008 academic year, 20\% of these students were ranked among the top 25 percentile rank in their high school class. In addition, the growth rate of this category of students was the highest, exceeding the $72 \%$ since the establishment of this private university. Table 2 and Figure 1 illustrate the data of enrollees according to their school rank.

Table 2: Longitudinal Count of Enrollees at Below and Top 25 Percentile Score

\begin{tabular}{|c|c|c|c|c|}
\hline Year & Below the 25 percentile score & \% Growth & Above the 25 percentile Score & \% Growth \\
\hline $2000-2001$ & 224 & & 47 & 2.12 \\
\hline $2001-2002$ & 202 & -9.82 & 48 & -31.25 th \\
\hline $2002-2003$ & 134 & -33.66 & 45 & 36.36 \\
\hline $2003-2004$ & 193 & 44.029 & 39 & -13.33 \\
\hline $2004-2005$ & 147 & -23.83 & 55 & 41.02 \\
\hline $2005-2006$ & 215 & 46.25 th & 48 & -12.72 \\
\hline $2006-2007$ & 211 & -1.86 & 83 & 72.91 \\
\hline $2007-2008$ & 352 & 66.82 & & \\
\hline
\end{tabular}


Figure 1

Percentage of Enrollees at Below and Top 25 Percentile Score

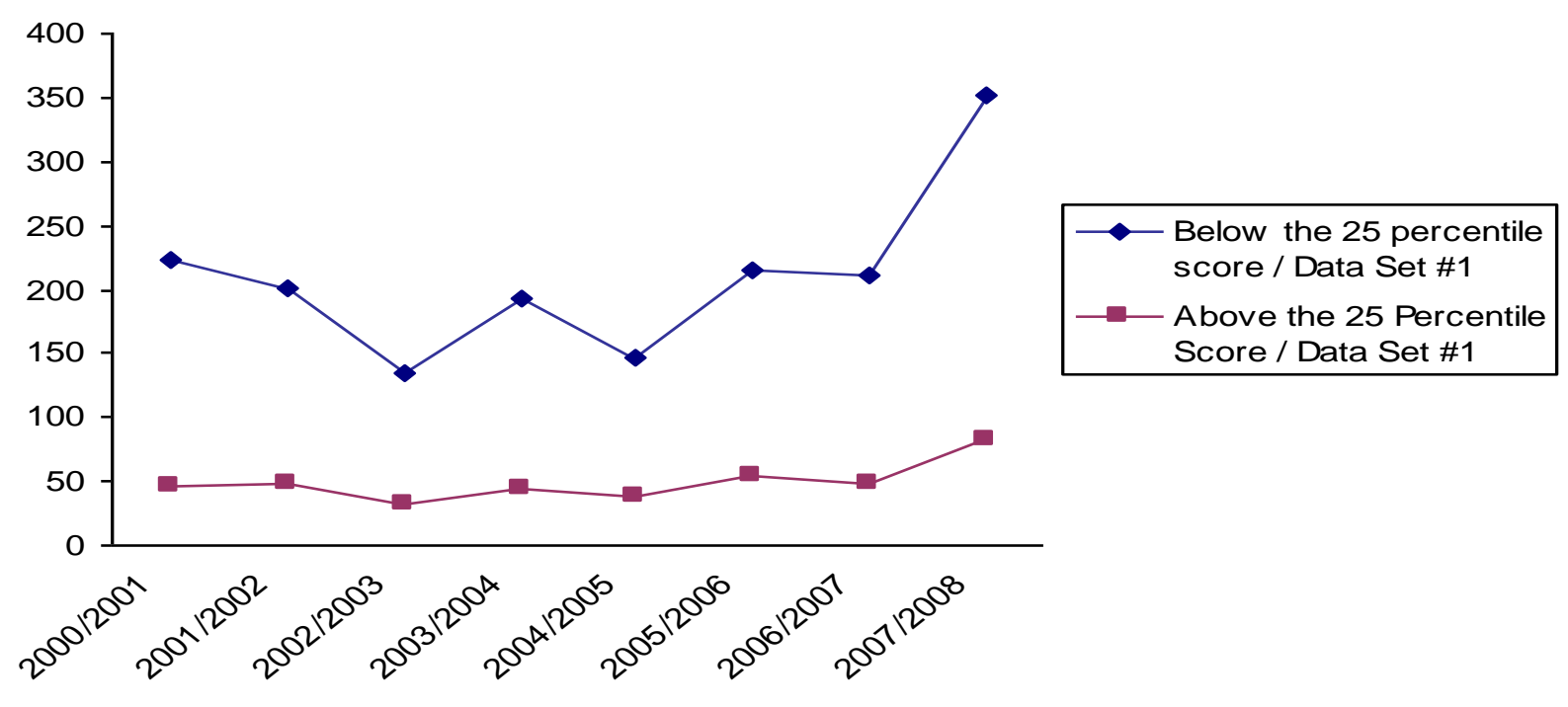

The number of top 25 percentile rank in their high school class enrolled at the university has practically doubled with respect to the previous academic year where the early admission call-up was not initiated yet. Moreover, crucial has been the mutation of high school averages for students ranked above the 25 percentile score after the early admission call-up. The results illustrated in Table 3 suggest a rise in student academic performance. An increase of 14 points in high school averages when 2007-2008 is compared to 2006-2007 has been noticed. For students below the 25 percentile score, there has been a significant increase of $68 \%$ (from an average of 37.2 in 2006-2007 to 62 in 2007-2008) in the high school averages. Table 3 reports high school averages for those students who scored below and above the 25 percentile score.

Table 3: High school Averages Below and at The Top 25 Percentile Score

\begin{tabular}{|l|c|c|c|}
\hline & Below the 25 percentile score & Above the 25 percentile Score & Overall average \\
\hline $\mathbf{2 0 0 0 - 2 0 0 1}$ & 32.49 & 57.60 & 36.81 \\
\hline $\mathbf{2 0 0 1 - 2 0 0 2}$ & 34.02 & 72.06 & 40.85 \\
\hline $\mathbf{2 0 0 2 - 2 0 0 3}$ & 40.10 & 67.34 & 44.57 \\
\hline $\mathbf{2 0 0 3 - 2 0 0 4}$ & 43.58 & 69.23 & 49.06 \\
\hline $\mathbf{2 0 0 4 - 2 0 0 5}$ & 42.72 & 65.66 & 46.10 \\
\hline $\mathbf{2 0 0 5 - 2 0 0 6}$ & 49.87 & 69.21 & 53.52 \\
\hline $\mathbf{2 0 0 6 - 2 0 0 7}$ & 37.20 & 58.78 & 41.44 \\
\hline $\mathbf{2 0 0 7 - 2 0 0 8}$ & 62.03 & 72.14 & 64.00 \\
\hline
\end{tabular}

The final analysis compared those students ranked at the top 25 percentile rank in high school that received the early admission call-up with the top 25 percentile score who did not receive the early admission call-up prior to 2007-2008 academic years. Those who received the early admission call-up had the highest averages compared to the top 25 percentile group who did not receive the call-up. 
Figure 2

Trend line for the Longitudinal High School Averages of Students who Ranked Below and Above the 25 Percentile Score

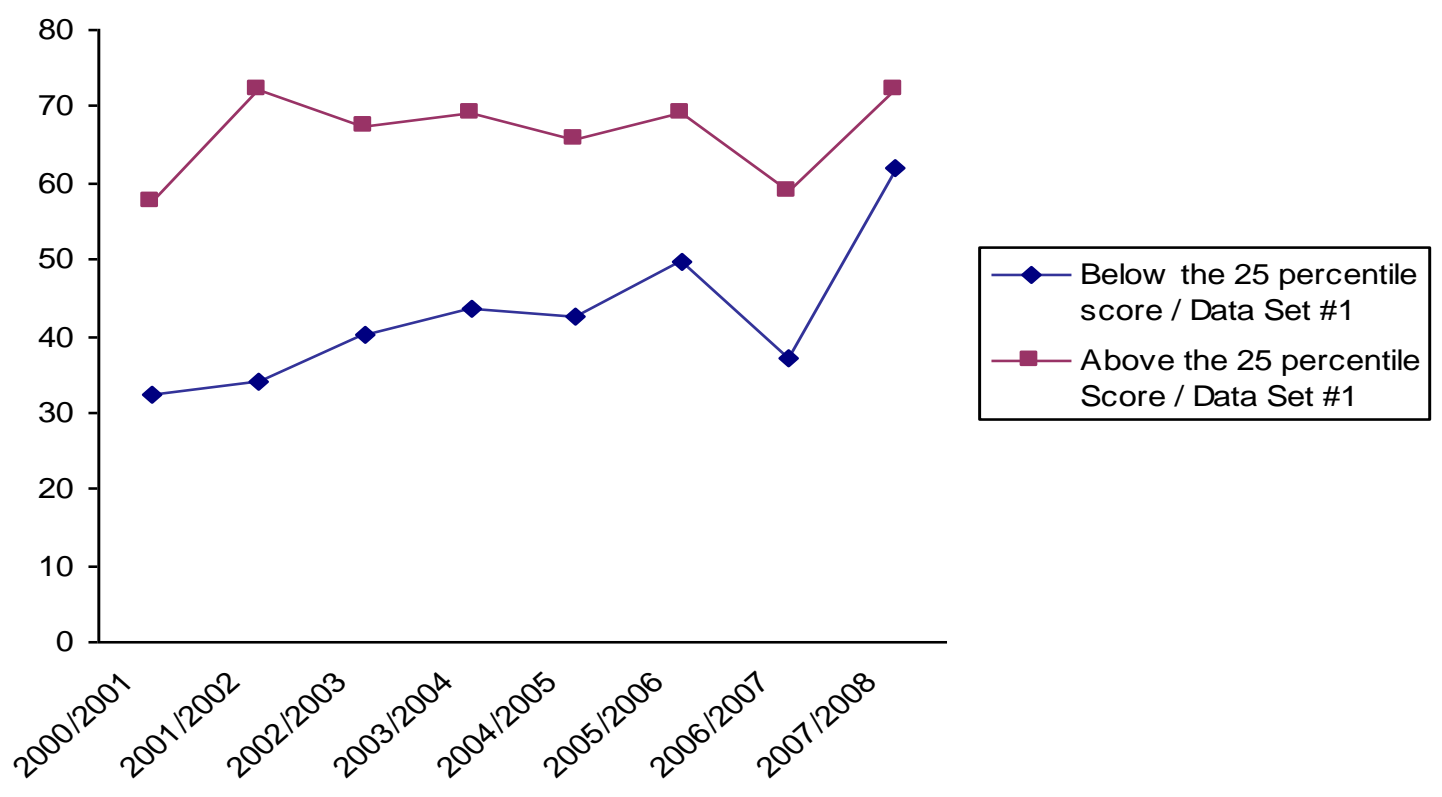

Table 4: Comparison on high school averages based on three conditions

\begin{tabular}{|l|c|c|}
\hline & No early admission call-up 2000-2006) & Early admission call-up (2007-2008) \\
\hline Rank below the 25 percentile score & 39.95 & 72.14 \\
\hline Rank above the 25 percentile score & 65.64 & \\
\hline
\end{tabular}

\section{DISCUSSION AND CONCLUSION}

The implementation of merit-based early admission on high school rank was effective in increasing enrollment of top-ranking students. For the past seven years high school averages of students who ranked below the 25 percentile score increased by $68 \%$ and was higher than students who where below the top 25 percentile score. It is clear that this university tried through the implementation of the early admission strategy to start a quality check program having in mind the scope of enrolling "better" students. Indeed and as previously measured, $20 \%$ of the university top feeder school enrollees were at the top 25 percentile rank in their school. Given the severe competition among Lebanese universities looking for top ranked students, early admission provided not only to attract such students, but also increased its enrollment; Those who applied to the university and received the early admission call-up were more likely to enroll than not enroll.

The challenge of early admission call-up to select students who are most likely to make a significant contribution to their field of study, has been translated in a first step by a significant increase of 14 average points of high school averages. Attracting students requires stronger academic programs and calls the university to commit itself to these better students. Avery, Zechauser, et. al. (2003) study explored these aspects in more than 500,000 college applicants and found that early admission practices has had a significant role in attracting students to top universities in the US. We see that early admission call-up may have the advantage over regular admission, as early admission call-up seems to play more than one role; by changing the characteristics of the student body while pushing the university to excel in designing its programs and curriculum.

However, there might be a drawback to early-call up for reasons that students with high school aptitude 
scores nearing borderline might not be identified early at the top 25 percentile rank in schools. Second, those who are in the top percentile scores may not score in the top 25 percentile in the national exams or the standardized tests which are usually taken upon the completion of secondary school in Lebanon and well beyond the period of preadmission call-up. According to Reingold (2004), the Ivy League universities are now considering dropping early admission in that students tend to choose too soon their colleges so that neither the college nor the student may have the right commitment. In fact in 2002, Yale University and Stanford University have dropped early admission programs. Others, such as Harvard and Princeton and many US universities have followed through; a move to end the early access ends a history for the advantaged students and thus pools everybody in one admission basket. The move to eliminate early admission in the Ivy League colleges has trickled down to many US universities (Venegas, 2006). However, in many universities seeking top students it might be just the right perk to attract these students and thus to entice them into applying and seeking admission to a program of choice.

\section{AUTHOR INFORMATION}

Viviane Youssef Naïmy is presently professor of Finance at Notre Dame University. She has published articles in a number of professional journals in the area of risk management, investment, corporate finance and financial modelling. Her current interests are in spreadsheet modeling, ALM, and derivatives. She was recognized for superior teaching; she received more than seven international awards in recognition of Excellence in Research. She worked for several banks and launched the first Mutual Fund in Lebanon and has structured one of the largest syndicated loans. For the World Bank, she assessed the feasibility of introducing the securitization process in the banking sector in Lebanon

\section{REFERENCES}

1. Avery, C., Zeckauser, R. \& Fairbanks, A. (2003). The early admissions game: Joining the elite. Cambridge, MA: Harvard University Press.

2. Anonymous (1999) "Why few Blacks apply for early admission." The Journal of Blacks in Higher Education, Vol. 24, pp. 66-68.

3. Berger, J. \& Milem, J. (2000). "Exploring the impact of historically Black colleges in promoting the development of undergraduates' self-concept." Journal of College Student Development, Vol. 41, 381-394.

4. Harman, G. (1994). Student selection and admission to Higher Education: policies and practices in the Asian region. Higher Education, Vol. 27, No. 3, pp. 313-339.

5. Reingold, D. (2004). How to Humanize the College Admission Game (EJ682491). Add. Journal of College Admission, Vol. 184, 18-22.

6. Venegas, K. (2006). Harvard, Princeton Drop Early Admissions - Should Others Follow? Diverse Issues in Higher Education, 23(19), 41. 